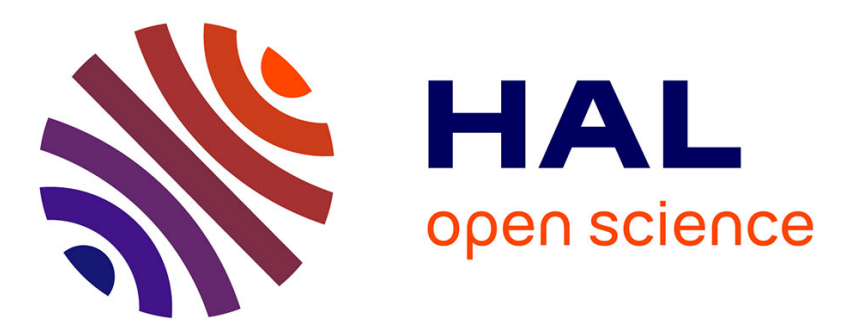

\title{
Effect of Temperature on Fretting Fatigue Characteristics of Bismaleimide Matrix
}

Tatiana Tarasova, Svetlana Terekhina, Michelle Salvia, Galina Malysheva

\section{To cite this version:}

Tatiana Tarasova, Svetlana Terekhina, Michelle Salvia, Galina Malysheva. Effect of Temperature on Fretting Fatigue Characteristics of Bismaleimide Matrix. Journal of Friction and Wear, 2013, 34 (3), pp.225-231. 10.3103/s1068366613030136 . hal-03473182

\section{HAL Id: hal-03473182 \\ https://hal.science/hal-03473182}

Submitted on 9 Dec 2021

HAL is a multi-disciplinary open access archive for the deposit and dissemination of scientific research documents, whether they are published or not. The documents may come from teaching and research institutions in France or abroad, or from public or private research centers.
L'archive ouverte pluridisciplinaire HAL, est destinée au dépôt et à la diffusion de documents scientifiques de niveau recherche, publiés ou non, émanant des établissements d'enseignement et de recherche français ou étrangers, des laboratoires publics ou privés. 


\title{
Effect of Temperature on Fretting Fatigue Characteristics of Bismaleimide Matrix
}

\author{
T. V. Tarasova ${ }^{a}$ *, S. M. Terekhina ${ }^{b}$, M. Salvia ${ }^{c}$, and G. V. Malysheva ${ }^{d}$ \\ ${ }^{a}$ Stankin Moscow State University of Technology, Vadkovskii per. 1, Moscow, 127994 Russia \\ ${ }^{b}$ Arts et Mètiers ParisTech, LAMPA, 2 boulevard du Ronceray, BP 93525, Angers, 49035 France \\ ${ }^{c}$ Laboratoire de Tribologie et Dynamique des Systèmes, UMR CNRS ECL ENISE, ENSMSE 5513, \\ École Centrale de Lyon, Ecully cedex, 69134 France \\ ${ }^{d}$ Bauman Moscow State Technical University, Vtoraya Baumanskaya ul. 5, Moscow, 105005 Russia \\ *e-mail: tarasova952@mail.ru
}

\begin{abstract}
For industrial composite structures, fretting friction is a critical problem. Thermosetting resins are promising materials for these structures due to good mechanical and thermal properties. Two mechanisms of the propagation of fatigue cracks in bismaleimide resin, i.e., the effect of the temperature and the type of the stress ate studied.
\end{abstract}

Keywords: fretting friction, thermosetting resins, fatigue cracks

DOI: $10.3103 / \mathrm{S} 1068366613030136$

\section{INTRODUCTION}

In modern industry, especially aircraft industry, increasingly lighter materials continue to grow in popularity. This strategy requires the replacement of metal alloys by organic and ceramic composites [1-3]. During operation, these materials experience severe vibration and the effect of elevated temperatures [4, 5], which results in so-called fretting friction on contact spots. Fretting is a contact-loading phenomenon characterized by oscillation relative movement with a very low amplitude that leads to the surface nucleation of cracks and/or wear in the contact of two surfaces. It is shown that, during fretting, modes of fracture are governed by the amplitude of displacement. Low amplitudes cause partial sliding in the contact zone. In this case, the contact zone consists of the stationary central area and the surrounding annular sliding area. This sliding condition is characterized by a fretting loop of a closed elliptical shape, i.e., the ratio of the friction force to the applied displacement and favors the nucleation and propagation of cracks. As soon as the amplitude of displacements begins to exceed the transition region of the amplitude of displacement $\delta_{t}$, the global sliding condition becomes valid in the contact zone. In this case, global sliding occurs within the whole contact zone and is characterized by a fretting loop of a quadratic shape. This mode of sliding is accompanied by increased energy of dissipation in the contact zone, as well as favors the formation of wear particles and their separation from the surface. Vingsbo and Soderberg [6], as well as Vincent et al. [7], supplemented this analysis with fretting maps that represented various sliding conditions and corresponding fracture modes as functions of the amplitude of displacement and the normal load (Fig. 1). Cracks mainly nucleate in the partial and mixed fretting modes, while wear occurs at high sliding amplitudes in the global sliding modes. In order to better understand a mechanism of the fracture of a composite material during fretting friction, it is initially necessary to study the behavior of the pure matrix.

The aim of this work is to investigate a temperature dependence of the fatigue characteristics of the thermosetting bismaleimide resin during fretting friction. These resins are characterized by high thermal stability at temperatures of up to $300^{\circ} \mathrm{C}$, which exceeds the limiting operational temperature for epoxy resins. In addition, bismaleimide resin has a high elastic modulus, excellent chemical resistance, good fatigue endurance, and light weight $[8,9]$. In this work, two mechanisms of the propagation of fatigue cracks are studied and the effect of the temperature and the type of the stress on the propagation of the cracks during fretting friction is shown.

\section{METHODS}

The nucleation and propagation of cracks were studied using a NENE electrodynamic vibrational system (Fig. 2). During its operation, the normal force $P$ is kept constant, while the friction force $Q$ and the displacement $\delta$ change. Therefore, the hysteresis loop $Q-\delta$ can be recorded by a software program used to 


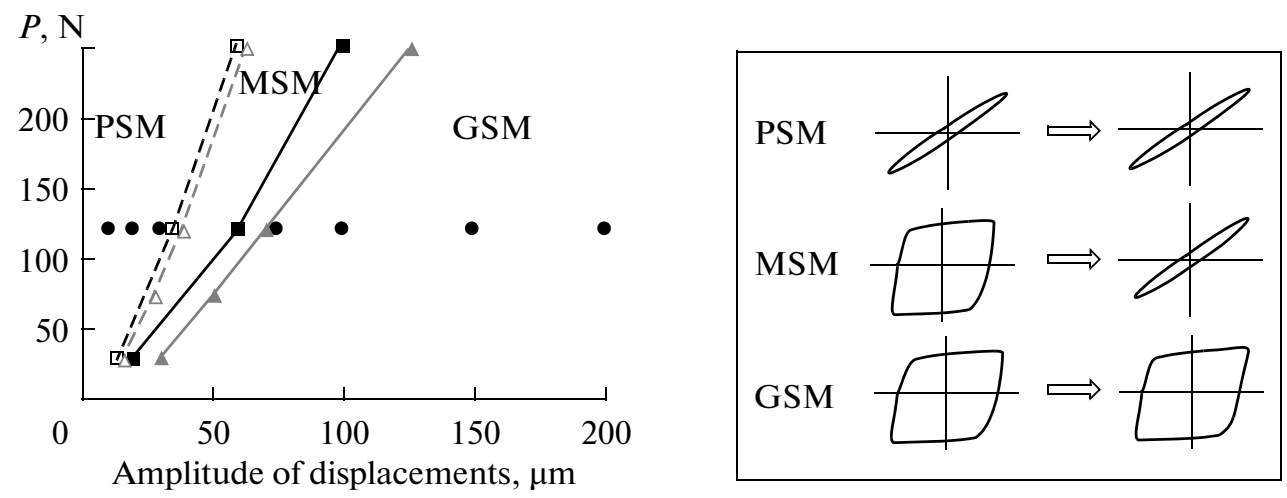

Fig. 1. Fretting maps of contact of bismaleimide resin with bearing steel for various temperatures: (PSM) partial sliding mode; (MSM) mixed sliding mode; (GSM) global sliding mode; black circles are experimental points corresponding to process of crack nucleation.

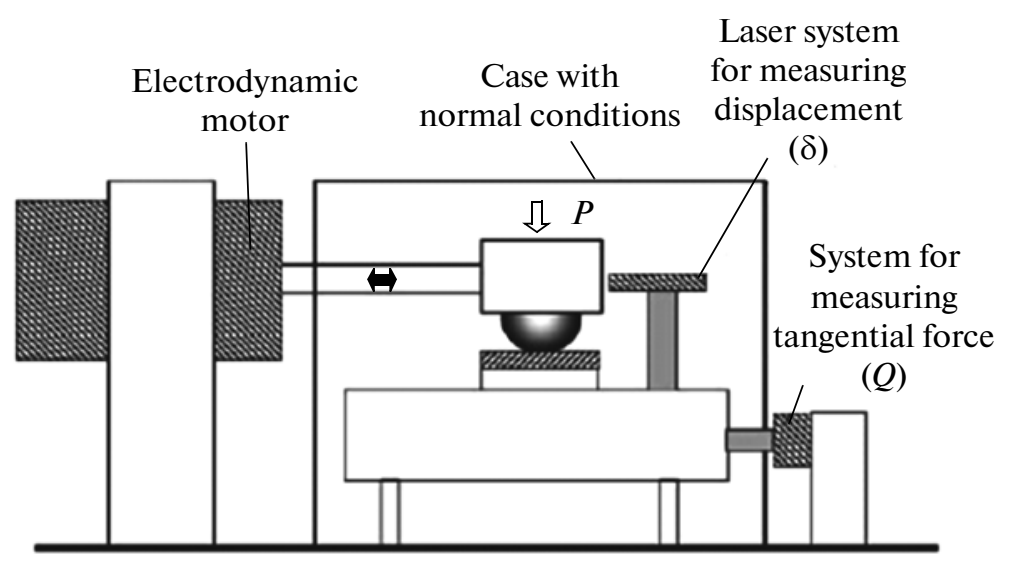

Fig. 2. Schematic of experimental setup.

obtain the numerical variables that include the energy of dissipation $E d$, i.e., the area of the hysteresis loop (which is also related to the friction work done in a single fretting cycle); the sliding amplitude $\delta_{0}$, i.e., the residual displacement at $Q=0$; the tangential force amplitude $Q^{*}$; and the displacement amplitude $\delta^{*}$.

The ball-on-plane arrangement was employed. The operating principle was based on the movement of a bearing steel specimen with a radius of $22.22 \mathrm{~mm}$ over a $4.1 \times 20 \times 25 \mathrm{~mm}$ rectangular polymer specimen under the effect of a constant normal load of $120 \mathrm{~N}$ (88.5 MPa). During tests, constant and variable displacement amplitudes were superimposed. In all tests described in this work, the frequency of the friction force was $10 \mathrm{~Hz}$. In order to study the effect of the temperature on the propagation of cracks, the tests were carried out in a closed chamber with a constant relative humidity of $40-50 \%$ under room conditions, as well as at temperatures of 90 and $190^{\circ} \mathrm{C}$. A qualitative analysis of cracks is based on the measurement of the maximum surface length of a crack $l$, which is the first to nucleate at the boundary of the contact along the sliding direction and perpendicularly propagates the fretting stresses (Fig. 3).

When we speak of crack analysis, we usually mean the measurement of the length of a subsurface crack $(b, \mathrm{~mm})$. However, the measurement of such a crack requires the long and thorough preparation of the cross-section surface, while the length of surface cracks can be directly measured by an optical or electron microscope. In order to establish an interrelation between these two values and to characterize the morphology of a subsurface crack, some cross sections of experimental specimens were examined (Table 1).

The slope of these cracks is practically perpendicular to the surface plane $\left(<15^{\circ}\right)$ (Fig. $\left.4 a\right)$. Figure $4 b$ confirms an almost linear correlation between $l$ and $b$. In other words, in the three-dimensional space, the morphology of a crack is presented by an elliptical shape at least in the studied length range. Therefore, the length of a subsurface crack can be expressed through the length of a surface crack as follows:

$$
b=H l \text {, where } H=0.0814 \text {. }
$$




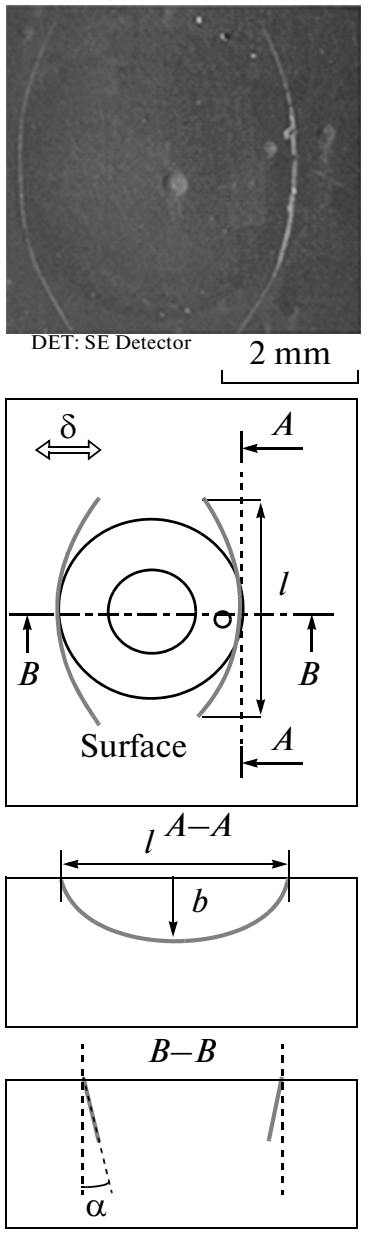

Fig. 3. Schematic description of morphology of primary cracks: $l$ is surface crack length; $b$ is subsurface crack length.

\section{MATERIALS}

The HexPly ${ }^{\circledR}$ M61 bismaleimide resin (Hexcel Co., France) was tested for fretting. A standard vulcanization cycle of this resin included the stage of preparing the resin in an autoclave at a temperature of $190^{\circ} \mathrm{C}$ for $4 \mathrm{~h}$ followed by independent vulcanization out of the autoclave at a temperature of $220^{\circ} \mathrm{C}$ for $16 \mathrm{~h}$; the heating rate was $1 \mathrm{~K} / \mathrm{min}$. During the fretting tests of this resin, a bearing steel counterbody was (a)

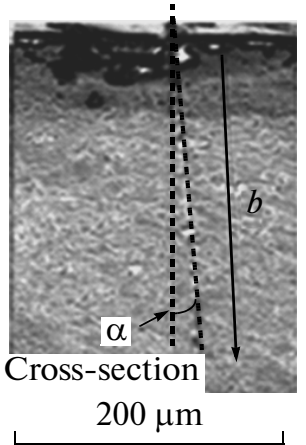

(b)

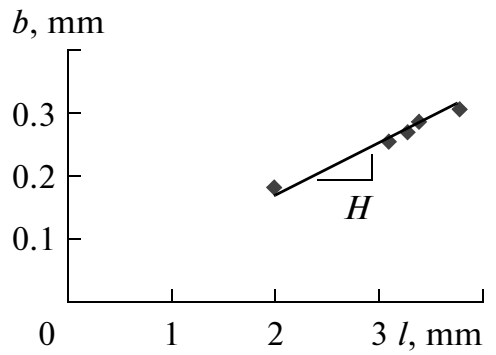

Fig. 4. (a) Surface of cross section of specimen with crack $\left(\delta= \pm 30 \mu \mathrm{m}, P=120 \mathrm{~N}, N=10^{4}\right.$ cycles, $\left.t=20^{\circ} \mathrm{C}\right)$; (b) ratio of subsurface crack length $b$ to surface crack length $l$ (Table 1$)$.

used. Table 2 presents the mechanical characteristics of the materials.

\section{RESULTS AND DISCUSSION \\ Description of Crack Propagation}

Using electron microscopy, it has been found that, irrespective of fretting friction modes and the temperature, the nucleation and propagation of two symmetric cracks located at the boundaries of the contact along the central axis are first to be observed (Fig. 5a). Here and below, these cracks, referred to as "primary cracks," propagate by the progressive fatigue mechanism perpendicularly to the sliding direction. They are observed under all sliding conditions at a fairly great friction force. Observations of the cross sections have also revealed the appearance of so-called numerous secondary microcracks. The location of these microcracks depends on the sliding region; in the partial sliding mode, they are restricted to the sliding ring, but, in the global sliding mode, they appear over the whole contact zone (Fig. 5b). These microcracks are usually very short (shorter than $5 \mu \mathrm{m}$ ) and are located at an angle of $45^{\circ}$ to the surface plane. This packet of the microcracks favors the separation of fatigue particles and the formation of a protective third body layer with time (Fig. 5c). Since these secondary microcracks

Table 1. The behavior of a crack in contact of bismaleimide resin with bearing steel under steady partial sliding condition ( $a$ is contact zone radius and $c$ is radius of stationary contact zone in partial fretting mode)

\begin{tabular}{c|c|c|c|c|c|c|l|l|l|c}
\hline$\delta^{*}, \pm \mu \mathrm{m}$ & $P, \mathrm{~N}$ & $Q, \mathrm{~N}$ & $N$, cycles & $T,{ }^{\circ} \mathrm{C}$ & $a, \mathrm{~mm}$ & $c, \mathrm{~mm}$ & $c / a$ & $l, \mathrm{~mm}$ & $b, \mathrm{~mm}$ & $\alpha, \mathrm{deg}$ \\
\hline 30 & 120 & 94 & 80000 & 20 & 0.8 & 0.7 & 0.88 & 2 & 0.18 & 84 \\
30 & 120 & 96 & 10000 & 90 & 0.8 & 0.7 & 0.88 & 3.1 & 0.253 & 84 \\
30 & 120 & 96 & 80000 & 90 & 0.8 & 0.7 & 0.88 & 3.4 & 0.28 & 85 \\
30 & 120 & 84 & 7000 & 190 & 0.9 & 0.83 & 0.92 & 3.3 & 0.265 & 87 \\
30 & 120 & 81 & 80000 & 190 & 0.9 & 0.8 & 0.89 & 3.8 & 0.3 & 87 \\
\hline
\end{tabular}


Table 2. Mechanical characteristics of bearing steel and bismaleimide resin at room temperature (temperature of bismaleimide resin $T_{\alpha}$ corresponds to glass transition temperature at frequency of $10 \mathrm{~Hz}$ )

\begin{tabular}{c|c|c|c|c|c|c|c}
\hline \multicolumn{1}{c|}{ Materials } & $E, \mathrm{GPa}$ & $v$ & $\sigma_{\mathrm{u}}, \mathrm{MPa}$ & $\sigma_{0.2}, \mathrm{MPa}$ & $R_{a}, \mu \mathrm{m}$ & $\mathrm{Hardness}$ & $T_{\alpha},{ }^{\circ} \mathrm{C}$ \\
\hline AISI 52100 & 210 & 0.3 & 2200 & 2000 & 0.1 & $60-67 H R C$ & - \\
Bismaleimide resin & $3.58(V=0.1 \mathrm{~mm} / \mathrm{min})$ & 0.35 & $35(V=0.1 \mathrm{~mm} / \mathrm{min})$ & - & 0.778 & $81 \mathrm{Shore} \mathrm{D}$ & 265 \\
\hline
\end{tabular}

have a slight effect on the contact zone as a whole, this analysis will mainly be focused on the phenomenon of the nucleation and propagation of primary cracks.

\section{Dynamic Analysis of Crack Propagation}

The dependence of the process of the propagation of fretting cracks on the cyclic shear of the surface and the friction force amplitude is studied. Figure 6a shows the dependence of the friction force on the number of fretting cycles at two constant amplitudes, including the global and mixed sliding modes, respectively. The observed differences in the process of the propagation of fretting cracks are due to the dependence on fluctuations of the coefficient of friction resulting from surface fracture during global sliding. In the global sliding mode, the coefficient of friction has reached the maximum value for less than 2000 cycles (from $\mu=0.3$ to 0.83 ). It then decreases to 0.8 and becomes stabilized because of the formation of a third body. Initially, the mixed sliding mode demonstrates a similar behavior of this process. However, as soon as the coefficient of friction reaches a transition value at which the contact tends to the partial sliding condition, the friction force becomes stabilized. It should be noted that, after the transition to the partial sliding region, the ratio $Q^{*} / P$ (a)

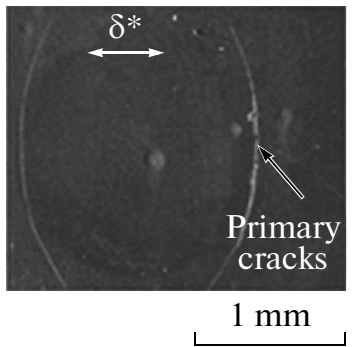

(b)

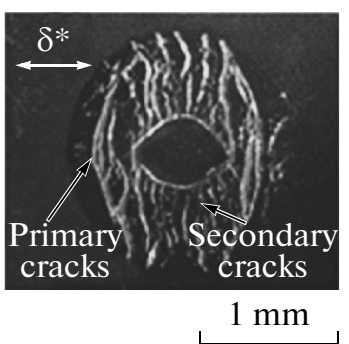

(c)

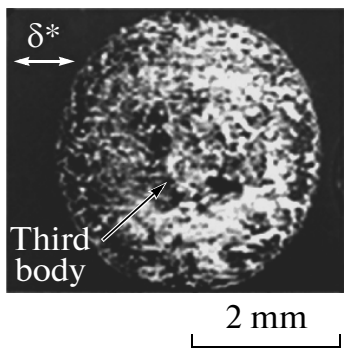

Fig. 5. Nucleation and propagation of cracks during fracture of polymer material: (a) propagation of primary cracks over boundaries of contact $\left(20^{\circ} \mathrm{C}, \delta^{*}= \pm 30 \mu \mathrm{m}, 10^{4}\right.$ cycles $)$; (b) propagation of secondary cracks in partial sliding mode $\left(20^{\circ} \mathrm{C}, \delta^{*}=\right.$ $\pm 30 \mu \mathrm{m}, 2 \times 10^{5}$ cycles $)$; (c) secondary cracks filled by third body in global sliding mode $\left(20^{\circ} \mathrm{C}, \delta^{*}= \pm 100 \mu \mathrm{m}, 2 \times 10^{5}\right.$ cycles $)$.

(a)

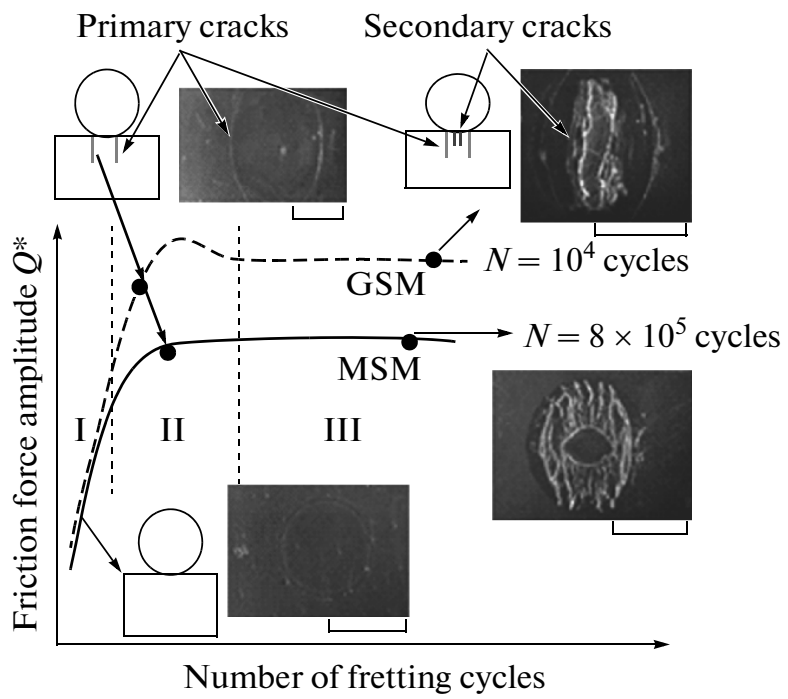

(b)

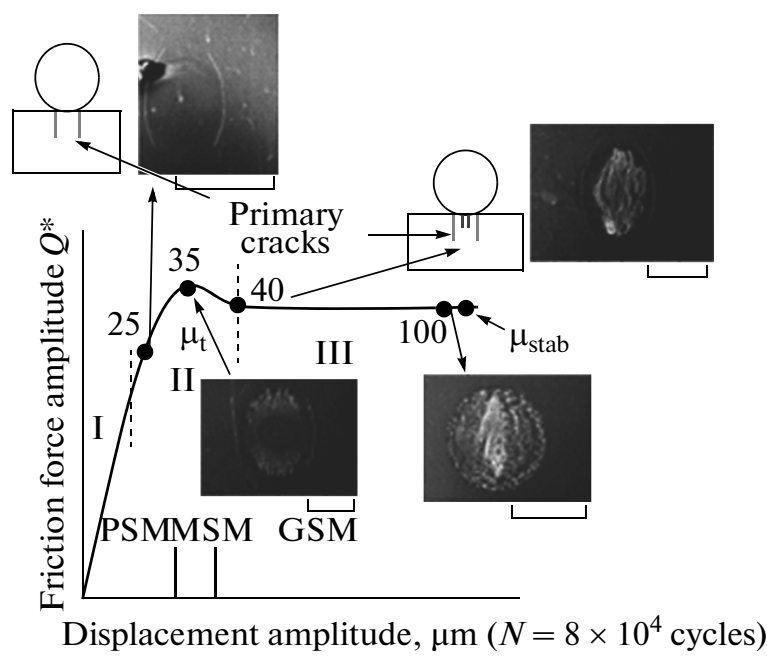

Fig. 6. Illustration of evolution of damage depending on friction force amplitude: (a) evolution depending on number of fretting cycles in global and mixed sliding modes; (b) evolution depending on displacement amplitude for given number of cycles in steady mode. 
(a)

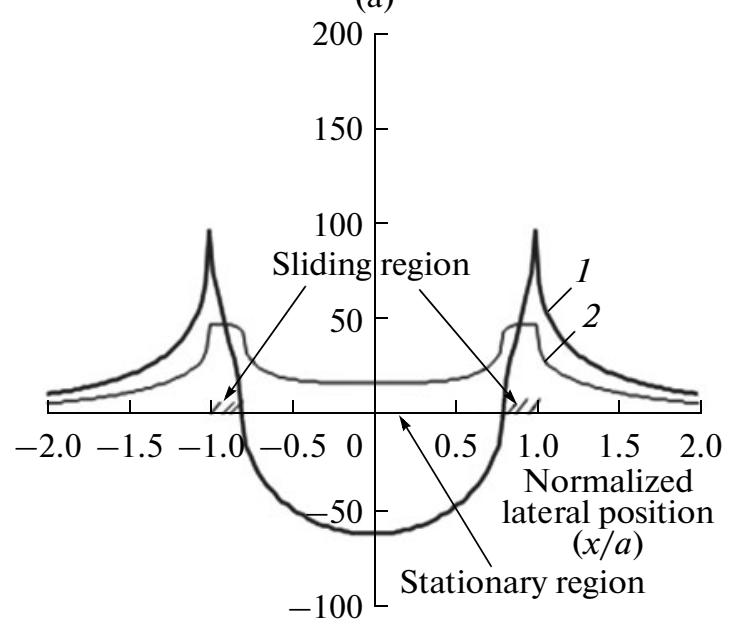

(b)

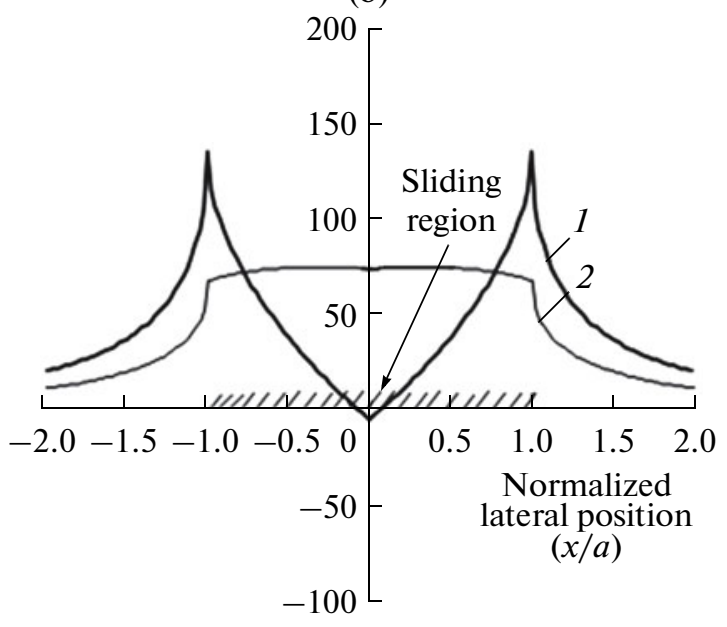

Fig. 7. Evolution of maximum surface stress depending on number of fretting cycles $\left((1) \sigma_{1 \text { max }}\right.$ is maximum principal stress, MPa; (2) $T_{\max }$ is maximum shear stress, MPa) for two presented sliding conditions (bismaleimide resin $\left(20^{\circ} \mathrm{C}\right) / \mathrm{bearing}$ steel, $R=$ $22.22 \mathrm{~mm}, P=120 \mathrm{~N}, a=807 \mu \mathrm{m}, p_{\max }=88 \mathrm{MPa}$ ): (a) partial sliding condition: $k=c / a=0.8, Q^{*} / \mu P=0.5$ and (b) global sliding condition: $k=c / a=0.0, Q^{*} / \mu P=1.0$.

can no longer be related to the coefficient of friction, since a part of the shear stress is controlled by elastic accommodation in the stationary contact zone.

As was expected, the fracture process can be controlled by the amplitude of contact stress and the loading history, i.e., the accumulation of damage. In the beginning of the tests and at low amplitudes of friction force, no damage is observed (region I). However, the higher the friction force amplitude, the more rapidly the nucleation of primary cracks takes place (region II). As was noted above, the nucleation of secondary cracks was controlled by stable sliding conditions. When partial sliding occurs, the secondary cracks are restricted to the outer sliding region of the contact zone; when global sliding occurs, the secondary cracks nucleate and propagate over the whole contact zone (region III).

The propagation of fretting cracks may also develop by a different mechanism. Figure $6 \mathrm{~b}$ shows the dependence of the steady friction force amplitude, i.e., the amplitude achieved after 50000 cycles on the superimposed displacement amplitude. During partial sliding, the friction force linearly increases until the maximum value is reached $\left(\mu_{\mathrm{t}}=0.83\right)$, which corresponds to transition to the mixed sliding mode. The friction force is them somewhat decreases and, when the global sliding occurs, gets stabilized at the value $\mu_{\text {stab }}=0.8$ at which a protective third body layer is formed. Therefore, during global sliding, the coefficient of friction is characterized by the value $\mu_{\text {stab }}$ in addition to the maximum transient state $\mu_{\mathrm{t}}$.

These values of the coefficient of friction are presented in Table 3 for different values of the temperature and normal load. As was mentioned above, it has been shown in this work that no cracks nucleate on the contact surface until the cyclic load of the friction force remains below the crack nucleation limit (I). Above this value, which is close to the mixed sliding mode, a primary crack occurs (II). As the friction force increases to the maximum value in the mixed sliding mode, the primary crack grows and secondary cracks simultaneously appear within the sliding ring (II). As soon as the contact zone transits to the global sliding mode, the secondary cracks propagate over the whole contact zone (III) (Fig. 6b).

In order to explain the nucleation of primary cracks, the surface distribution of the maximum Tresca tensile and shear stresses for two sliding conditions, i.e., partial and global sliding is presented in Fig. 7 with allowance for the Hertz-Mindlin elastic theory [10]. Subsurface stresses were calculated using the FORTRAN code that considered both the contact pressure and the surface shear stresses determined by the Mindlin expressions together with the analytical

Table 3. Coefficient of friction in transition from mixed to global sliding of contact of bismaleimide resin with bearing steel at various temperatures under various normal loads $(f=10 \mathrm{~Hz})$

\begin{tabular}{c|c|c|c|c}
\hline & $T,{ }^{\circ} \mathrm{C}$ & 20 & 90 & 190 \\
\hline$P=30 \mathrm{~N}$ & $\delta_{\mathrm{t}}( \pm \mu \mathrm{m})$ & 14 & 16 & \\
& $\mu_{\mathrm{t}}$ & $1.00 \pm 0.10$ & $1.2 \pm 0.05$ & \\
& $\mu_{\mathrm{stab}}$ & $1.08 \pm 0.02$ & $1.1 \pm 0.02$ & \\
\hline$P=120 \mathrm{~N}$ & $\delta_{\mathrm{t}}( \pm \mu \mathrm{m})$ & 35 & 38 & 50 \\
& $\mu_{\mathrm{t}}$ & $0.83 \pm 0.02$ & $0.86 \pm 0.02$ & $1.00 \pm 0.02$ \\
& $\mu_{\mathrm{stab}}$ & $0.80 \pm 0.02$ & $0.95 \pm 0.02$ & $1.09 \pm 0.02$ \\
\hline$P=250 \mathrm{~N}$ & $\delta_{\mathrm{t}}( \pm \mu \mathrm{m})$ & 60 & 62 & \\
& $\mu_{\mathrm{t}}$ & $0.76 \pm 0.02$ & $0.78 \pm 0.02$ & \\
& $\mu_{\mathrm{stab}}$ & $0.78 \pm 0.02$ & $0.80 \pm 0.02$ & \\
\hline
\end{tabular}



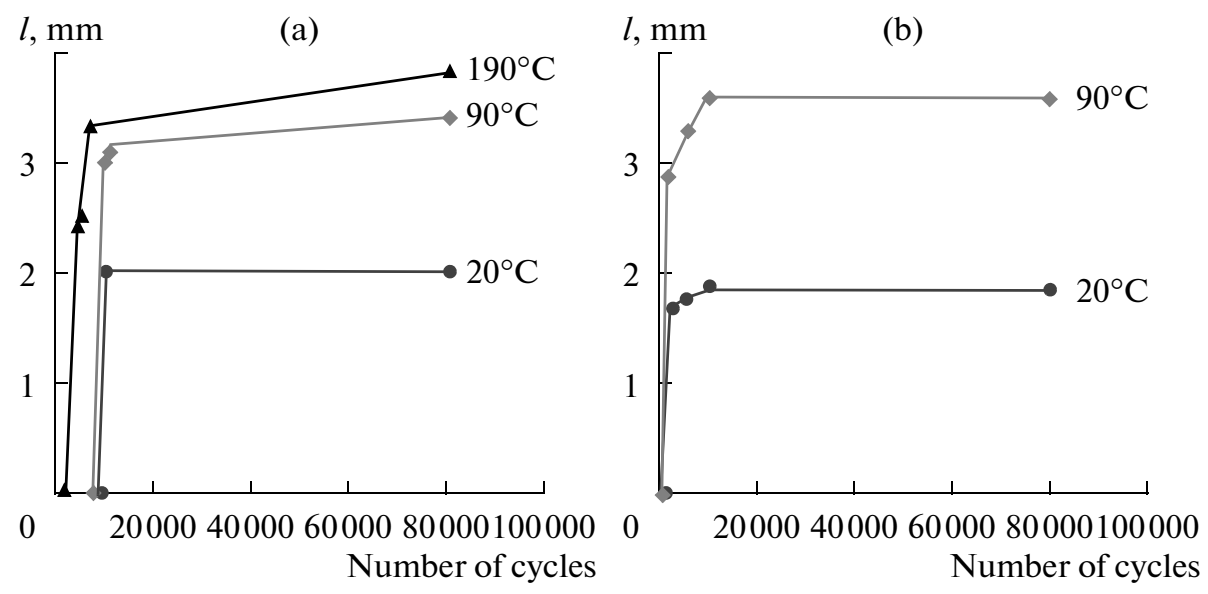

Fig. 8. Evolution of maximum surface crack length $l$ depending on number of cycles at various temperatures: (a) mixed sliding mode $\left(P=120 \mathrm{~N}, \delta^{*}=30 \mu \mathrm{m}, Q^{*} \approx 90 \mathrm{~N}\right.$ (average values) $)$; (b) global sliding mode $\left(P=120 \mathrm{~N}, \delta^{*}=120 \mu \mathrm{m}, Q^{*} \approx 100 \mathrm{~N}\right.$ (average values)).

Gamilton expressions for subsurface stresses etc. [11]. An analysis of the data obtained shows that the maximum tensile stresses arise at the boundaries of the contact, while the maximum shear stresses are uniformly distributed over the sliding region. For an undamaged surface, results of this analysis should be accepted with caution in the case of a long crack. Assuming that primary cracks permanently appear at the boundaries of the contact and propagate nearly perpendicularly to the contact surface, i.e., perpendicularly to the direction of the maximum principal stresses, it can be concluded that cracks in the bismaleimide resin, included the nucleation and propagation stages, are mainly controlled by the tensile stress component. This indicates the brittle behavior of the resin below the glass transition temperature $\left(T<T_{\alpha} \approx 265^{\circ} \mathrm{C}\right)$.

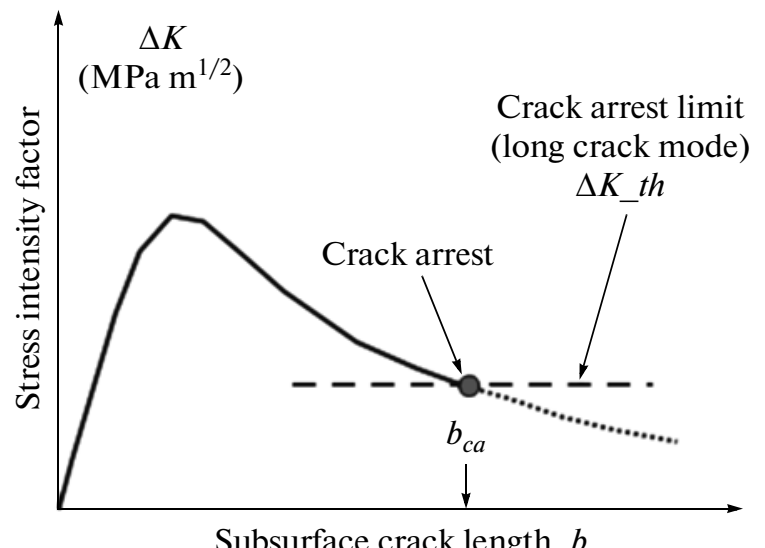

Fig. 9. Illustration of evolution of stress intensity factor depending on maximum crack length during plane fretting test (in accordance with [9]); $b_{c a}$ is steady maximum crack length with regard to condition of crack arrest (decrease in $\Delta K \_$th leads to increase in $b_{c a}$ ).

\section{Analysis of Propagation of Crack under Effect of Plane Fretting Stresses: Influence of Temperature on Condition of Crack Arrest}

In order to elucidate how the temperature affects the propagation of a crack, we carried out tests at temperatures of 20,90 , and $190^{\circ} \mathrm{C}$ for mixed (Fig. 8a, $\delta^{*}=30 \mu \mathrm{m}, Q^{*}=90 \mathrm{~N}$ ) and global (Fig. 8b, $\delta^{*}=$ $\left.100 \mu \mathrm{m}, Q^{*}=100 \mathrm{~N}\right)$ fretting modes of sliding. It has been found that, under the effect of plane fretting stresses, the crack initially propagates very rapidly and reaches a stable maximum length after 10000 cycles. This evolution of the length of the subsurface crack can be explained by the rate of its propagation (Fig. 9). An initial crack induced by the effect of the very critical contact stress is characterized by a high stress intensity function and, therefore, high propagation rates. However, under the surface, the contact stresses grow so that the deeper the crack, the lower the value of the stress intensity function. Figure 9 shows a progressive decrease in the rate of crack propagation.

The rate of crack propagation decreases until the superimposed value of $\Delta K$ remains less than the crack arrest limit $\Delta K_{-}$th below which the crack is arrested, i.e., when $\Delta K<\Delta K \_t h$ and $d b / d N=0$. This fact of crack arrest results in a permanent increase in the maximum crack length after $N>20000$ cycles. One of the interesting conclusions drawn from this analysis is that the maximum crack length $l c a$ is indirectly related to the crack arrest limit $\Delta K_{-} t h$. The greater the crack length $l c a$ the less is $\Delta K_{t} t h$. With allowance for results of studying the mixed sliding mode in which wear does not result in transformations on the contact surface $\left(\delta^{*}=30 \mu \mathrm{m}\right)$, at temperatures of 20,90 , and $190^{\circ} \mathrm{C}$, changes in the maximum crack arrest lengths are 2 , 3.2 , and $3.7 \mathrm{~mm}$, respectively. Since, at these temperatures, the superimposed cyclic amplitude of the friction force is nearly the same, it was supposed that the effect of the temperature substantially reduces the 
crack arrest limit for the bismaleimide resin $\Delta K_{-} t$ th. Between 20 and $90^{\circ} \mathrm{C}$, a decrease in this characteristic is very noticeable and, between 90 and $190^{\circ} \mathrm{C}$, it is less marked. It should be noted that, above $190^{\circ} \mathrm{C}$, the mechanical characteristics of the polymer material drop sharply; a slightest increase in the crack length can be due to a substantial decrease in the contact stress because of contact area expansion.

It should be noted in conclusion that a qualitative analysis of conditions of crack attest requires a complete viscoelastic plastic contact analysis to be carried out, including modeling a three-dimensional crack $[12,13]$. This complex study is beyond the scope of this work and, therefore, the analysis presented is restricted to quantitative description.

\section{CONCLUSIONS}

This work was aimed at investigating the contact fatigue behavior of the bismaleimide resin under the effect of plane fretting loads at various temperatures. It has been found that the nucleation and propagation of so-called primary cracks at the boundaries of the contact are one of the main mechanisms of fracture during the fretting friction of the bismaleimide resin. This location corresponds to the point of contact where high cyclic tensile stresses arise. For various sliding modes, three regions were determined that correspond to no damage, the nucleation of a crack, and the propagation of primary cracks at temperatures of 20, 90, and $190^{\circ} \mathrm{C}$. It has been found that, at temperatures of 90 and $190^{\circ} \mathrm{C}$, cracks nucleate and propagate faster than under normal conditions. This is explained by the brittle behavior of the bismaleimide matrix at $T<T_{\mathrm{g}}=$ $263^{\circ} \mathrm{C}$.

\section{REFERENCES}

1. Grigor'ev, S.N. and Krasnovskii, A.N., Directions of development of technology of object production from polymer composition materials by coiling method, Vestnik MGTU “Stankin", 2011, no. 3, pp. 95-98.

2. Grigor'ev, S.N., Kutin, A.A., and Skhirtladze, A.G., Training of technologists for modernization of machinebuilding complex of Russia, Spravochnik. Inzhenernyi Zhurnals Prilozheniem, 2011, no. 5, pp. 18-20.

3. Grigor'ev, S.N., Solution of machine engineering technological refinement problems, Vestnik MGTU "Stankin", 2008, no. 3, pp. 5-9.

4. Maslov, A.R., Measurement of the roughness parameters of a treated surface in turning parts fabricated from heat-resistant alloys, Measur. Techn., 2012, vol. 55, pp. 648-653.

5. Krasnovskii, A.N. and Grigoriev, S.N., A study of the process of continuous forming of nanocrystalline composite powders, Metal Sci. Heat Treat., 2012, vol. 54, pp. 13-16.

6. Vingsbo, O. and Soderberg, S., On fretting maps, Wear, 1998, vol. 126, pp. 131-147.

7. Vincent, L., Berthier, Y., and Godet, M., Testing methods in fretting fatigue: a critical appraisal, ASTM STP, 1992, vol. 1159, pp. 23-32.

8. Stenzenberger, H.D., in: Structural Adhesives: Developments in Resins and Primers, Kinloch, A.J., ed., Amsterdam: Elsevier, 1986.

9. Terekhina, S.M., Malysheva, G.V., Bulanov, I.M., and Tarasova, T.V., Investigation of tribological properties of polymer composite materials based on bismaleimide binder, Polymer Sci., Ser. D, 2011, vol. 4, pp. 136-137.

10. Mindlin, R., Compliance of elastic bodies in contact, J. Appl. Mech., 1949, vol. 16, pp. 259-268.

11. Hamilton, G.M., Explicit equations for the stresses beneath a sliding spherical contact, Proc. Inst. Mech. Eng. C, 1983, vol. 197, pp. 53-59.

12. Kremnev, L.S., On correlation of linear and nonlinear mechanics criteria of material failure, Materialovedenie, 2007 , no. 5 , pp. 31-38.

13. Grigor'ev, S.N. and Kuzin, V.V., Prospects for tools with ceramic cutting plates in modern metal working, Glass and Ceramics, 2011, no. 8, pp. 253-257.

Translated by D. Tkachuk 